\title{
Web Site Usability for Rare Book and Manuscript Libraries
}

THE INFORMATION PRESENTED on the Web sites of special collections libraries is often very different from the information included on the Web sites of general collections libraries. Descriptions of manuscripts, finding aids in HTML or PDF formats, Encoded Archival Description findings aids, short-title lists, and home-grown databases are among the diverse resources that may be found on Web sites of special collections libraries. Additionally, the Web site may be required to describe certain important sources of information that are not available online, such as finding aids in hard copy or a card catalog.

The library literature includes many studies of academic library Web sites but does not appear to address the question of whether or not special collections sites present unique issues. Are terms used in reference to rare books and manuscripts understood by users? Are users able to navigate the variety of resources that may be offered outside the online catalog? Can remote users easily find information about arranging a personal visit to the facility? This study was designed to gather practical qualitative data to inform the redesign of the Web site of Indiana University's Lilly Library and to reveal some of the usability issues particularly related to the Web sites of rare book and manuscript libraries.

\section{Literature Review}

"Usability" is a term that describes how easy an interface is to use. The principles of usability can help to evaluate many types of user interfaces, from the remote control of a DVD player to a commercial Web site. In addition to ease of use, the different elements that contribute to a measurement of usability can include effectiveness, efficiency, learnability, and user satisfaction. ${ }^{1}$

1. Jakob Nielsen is a well-known authority on Web usability. A concise introduction to the field is found on his Web site: Usability 101: Introduction to Usability, available online at www.useit.com/alertbox/20030825.html (accessed Sept. 5, 2008). 
The literature on Web usability is extensive. Nielsen, Rosenfeld and Morville, and Krug are among those who focus on the design of Web sites based upon the principles of Web usability. ${ }^{2}$ These principles can be used to evaluate how easily a site can be navigated, download times, specificity of labels and categories, and clear terminology, among many other issues. Usability testing for the Web involves observing real people performing real tasks at a particular Web site. This practice has been widely adopted in libraries for the development of Web sites, OPACs, and digital library interfaces. Both Pace and Campbell have edited guides to usability testing for libraries, including case studies and methods. ${ }^{3}$ Numerous journal articles also describe case studies; some also report specific findings. ${ }^{4}$

Studies in the library literature commonly identify problems with design, navigation, and terminology. Often, study participants have trouble understanding library terms and the categorization of information. Faculty and student participants tend to experience similar levels of difficulty, and many students demonstrate a preference for searching over browsing. ${ }^{5}$ Yet only a few of these studies specifically shed light on the usability of special collections library Web sites. Spivey examined sixty academic library homepages for instances of library idioms and vendor acronyms that might not be understood by Web users. ${ }^{6}$ Among the problematic library jargon, he cites the phrase "special collections," but he does not report detailed findings that could have shown how widely the phrase was used. Naismith and Stein administered a multiple-choice test to one hundred freshman students to assess their knowledge of terms gleaned from reference interviews and library handouts. ${ }^{7}$ The terms "primary source" and "university archives" were understood by 45 percent and 41 percent of students, respectively. The most understood term

2. Jakob Nielsen, Designing Web Usability (Indianapolis: New Riders, 2000); Louis Rosenfeld and Peter Morville, Information Architecture for the World Wide Web (Sebastopol, Calif.: O’Reilly Media, 2002); Steve Krug, Don't Make Me Think: A Common Sense Approach to Web Usability (Indianapolis: New Riders, 2000).

3. Andrew Pace, "Optimizing Library Web Services: A Usability Approach," Library Technology Reports, 38.2 (2002): 1-87; Usability Assessment of Library-Related Web Sites: Methods and Case Studies, ed. Nicole Campbell (Chicago: American Library Association, 2001).

4. Janet Chisman, Karen Diller, and Sharon Walbridge, "Usability Testing: A Case Study," College and Research Libraries 60.6 (1999): 552-69; Ruth Dickstein and Vicki Mills, "Usability Testing at the University of Arizona Library: How to Let Users in on the Design," Information Technology and Libraries 19.3 (Sept. 2000): 144-51; Candace Benjes and Janis F. Brown, "Test, Revise, Retest: Usability Testing and Library Web Sites," Internet Reference Services Quarterly 5.4 (2001): 37-54; and Brenda Battleson, Austin Booth, and Jane Weintrop, "Usability Testing of an Academic Library Web Site: A Case Study," Journal of Academic Librarianship 27.3 (2001): 188-98.

5. Susan McMullen, "Usability Testing in a Library Web Site Redesign Project," Reference Services Review 29.1 (2001): 7-22; Laura Cobus, Valeda Frances Dent, and Anita Ondrusek, "How Twenty-Eight Users Helped Redesign an Academic Library Web Site," Reference \& User Services Quarterly 44 (Spring 2005): 232-46; Louise McGillis and Elaine G. Toms, "Usability of the Academic Library Web Site: Implications for Design," College \& Research Libraries 64.4 (2001): 355-67.

6. Mark A. Spivey, "The Vocabulary of Library Home Pages: An Influence on Diverse and Remote End-Users," Information Technology and Libraries 19.3 (2000): 151-56.

7. Rachael Naismith and Joan Stein, "Library Jargon: Student Comprehension of Technical Language Used by Librarians," College and Research Libraries 50 (1989): 543-52. 
was "call number," with 83 percent; the least understood was "multivolume set," with 11 percent.

The archival community has published widely on user experience and the use of finding aids (on paper and in various electronic formats). American Archivist published a special section on "Users and Archival Research" that provides a good introduction to the ways archivists seek to understand their users. ${ }^{8}$ Yakel and Kim analyzed the Web sites of twelve state historical societies and state archives. ${ }^{9}$ They found the sites content-rich but marred by some common usability problems: lack of clear and consistent navigation, difficulty with determining where a researcher should begin a search, and pages overloaded with information. Prom tested eighty-nine users on four different archival Web sites, asking them to identify finding aids for specific collections and to select specific items within those finding aids. ${ }^{10}$ Users with either computer expertise or experience using archives were most successful in completing the tasks. Prom's results indicated the importance of browsing for finding known collection names and that users expect searching mechanisms and results to mimic Google. He also observed that navigation and searching within an individual finding aid is often problematic, especially for finding aids produced in PDF format.

\section{Lilly Library Study}

The Lilly Library is the principal rare books, manuscripts, and special collections library of Indiana University. Its collections consist of approximately 400,000 books, 7 million manuscripts, and 130,000 items of sheet music. Intellectual access to the library's diverse collections is provided through a variety of means: an online catalog, card catalog, typed short-title lists, Web-based resources, and in-house databases. The library's Web site facilitates access to a variety of online resources describing the library's collections and provides information on print resources available in the library reading room.

The study tested two different Web sites: the current Lilly Library Web site and a redesigned Web site. The current site debuted in 2001 and was based on staff comments and guidelines for designing Web sites, but no user testing was conducted. Since 2001, content on the site had expanded considerably, and some pages now required scrolling

8. The American Archivist 66.1 (2003) includes: Helen R. Tibbo, "Primarily History in America: How U.S. Historians Search for Primary Materials at the Dawn of the Digital Age"; Elizabeth Yakel and Deborah A. Torres, "AI: Archival Intelligence and User Experience"; Wendy M. Duff and Catherine A. Johnson, "Where Is the List with All the Names? Information-Seeking Behavior of Genealogists"; and Barbara L. Craig, "Perimeters with Fences? Or Thresholds with Doors? Two Views of a Border."

9. Elizabeth Yakel and Jihyun Kim, "Midwest State Archives on the Web: A Content and Impact Analysis," Archival Issues 28.1 (2003-2004): 47-62.

10. Christopher J. Prom, "User Interactions with Electronic Finding Aids in a Controlled Setting," American Archivist 67.2 (2004): 234-68. 


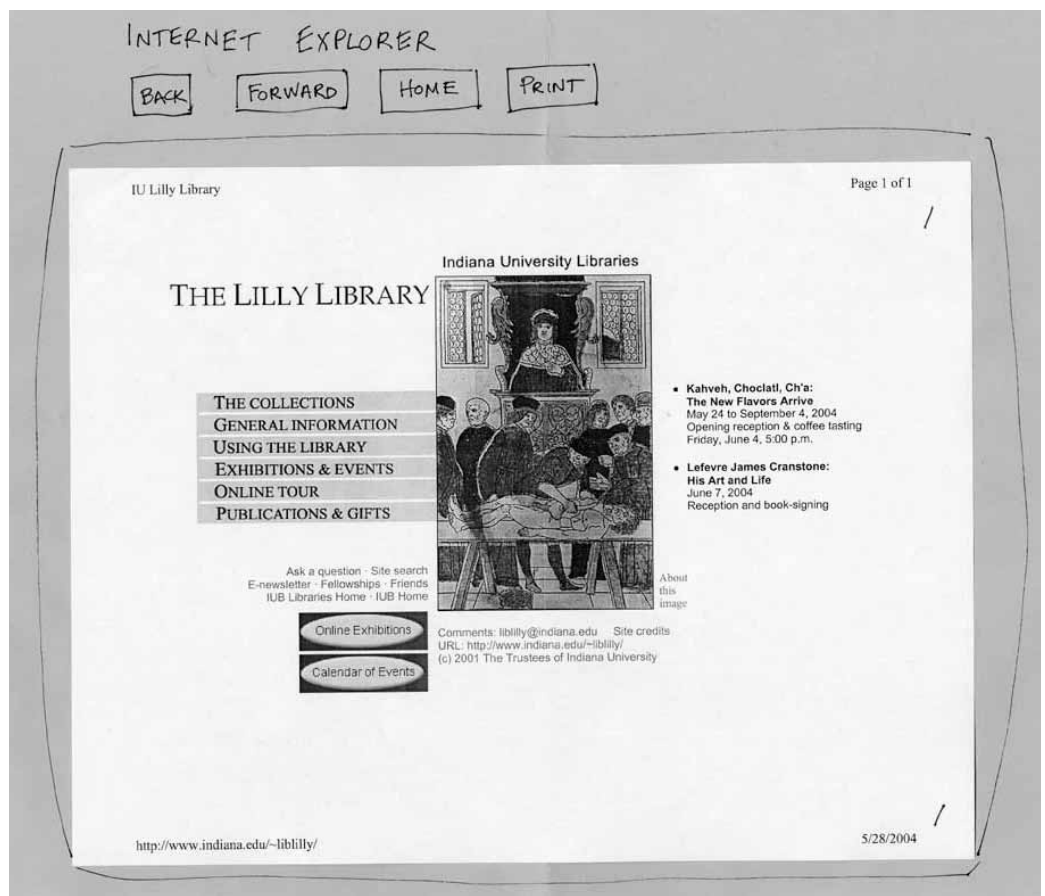

Illustration 1. Paper version of current Lilly Library homepage (Site A), with paper version of Web browser.

through several screens to view all the information. The redesigned site was intended to organize this content better and provide a more prominent role for searching. It replaced six main menu items with three and added an easily recognizable site search feature. "Find a book or manuscript" replaced "Collections." "Programs \& Services" subsumed four categories on the current site ("Using the Library," "Exhibitions \& Events," "Online Tour," and "Publications \& Gifts"). In some cases, information on lower-level pages in the new site was also reorganized. In particular, the current site's "Collections" page, renamed "Find a book or manuscript," was broken down into several pages to eliminate the need to scroll through multiple screens of information.

The first phase of the study used paper prototypes of the two different Web sites. A paper prototype is a model in which an electronic "page" is represented by words and images on a physical piece of paper. Instead of clicking a computer mouse, study participants point to the link they wish to select and a facilitator then presents them with a new paper Web page representing the destination of that link. The use of paper prototypes has several significant advantages. It allows one to test without investing time and effort in creating a functional electronic prototype. It also means that testers are not required to use computers. Paper prototyping can be especially helpful in the early stages of design. ${ }^{11}$

11. Carolyn Snyder, Paper Prototyping: The Fast and Easy Way to Design and Refine User Interfaces (San Francisco: Morgan Kaufmann, Elsevier Science, 2003). 


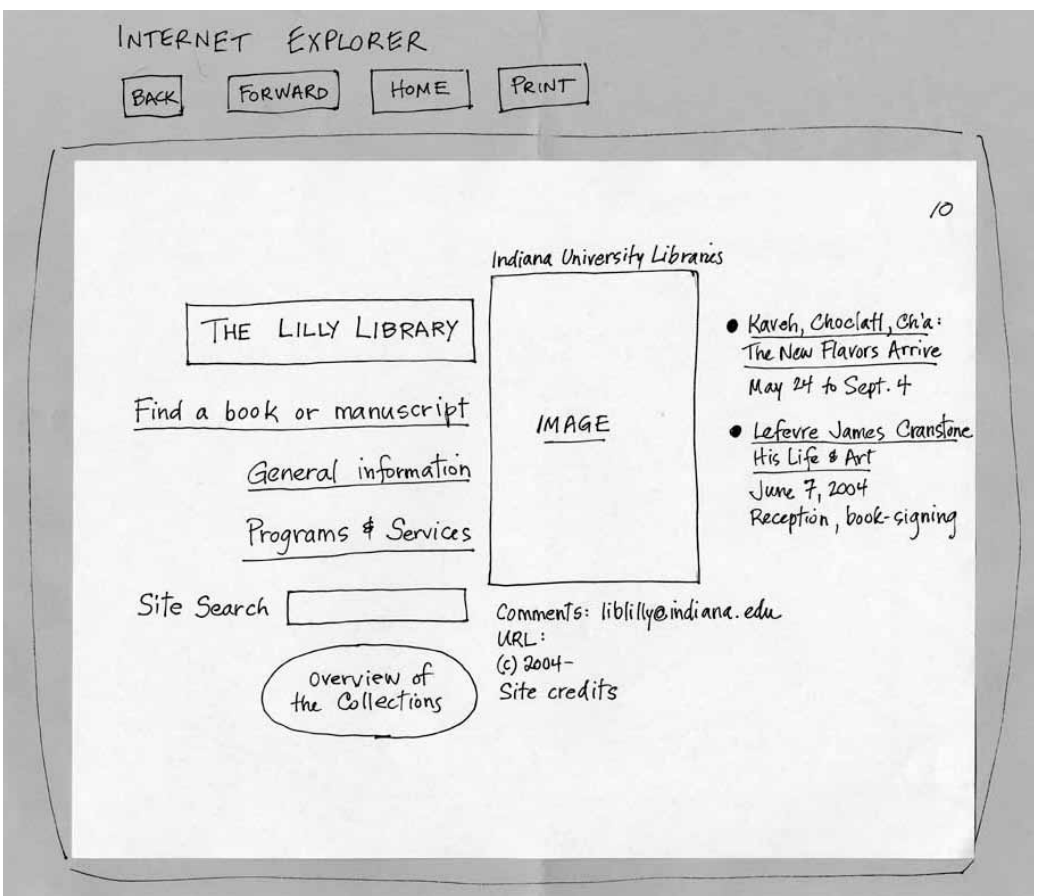

Illustration 2. Paper prototype of redesigned Lilly Library homepage (Site B).

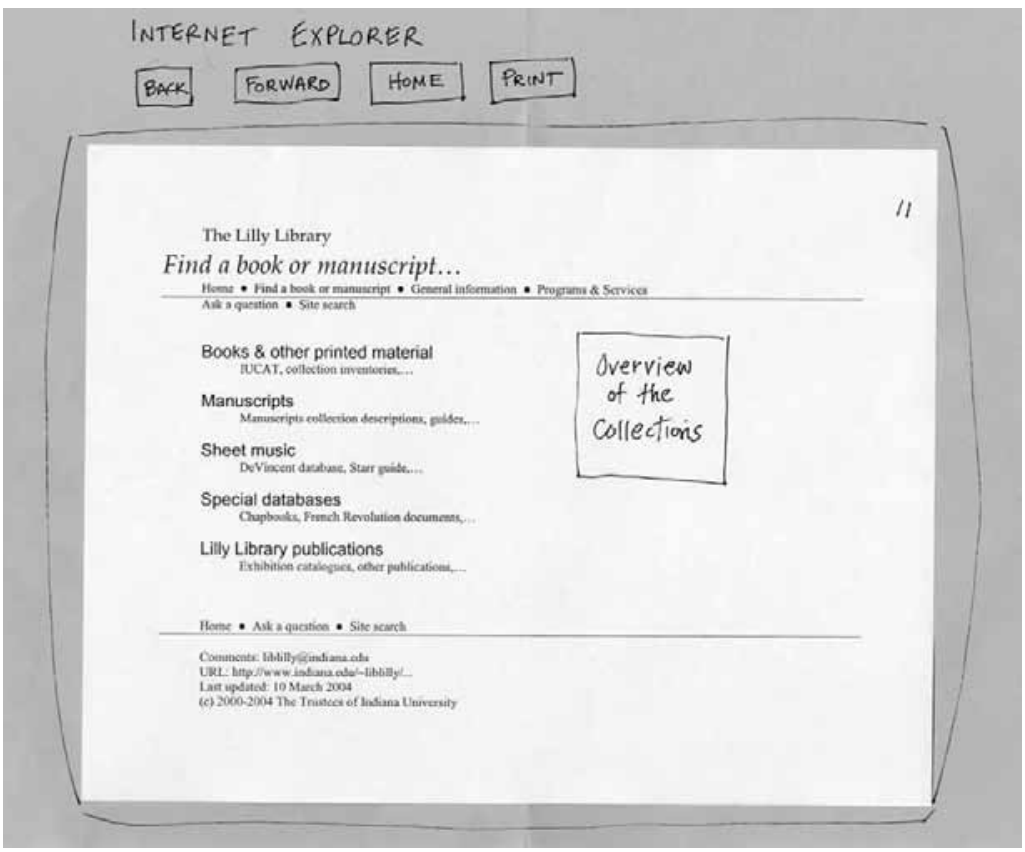

Illustration 3. Paper prototype of "Find a book or manuscript" page (Site B). 
The paper prototype of the current Lilly Library Web site consisted of printouts of the relevant parts of the site as well as printouts of relevant search screens. A hand-drawn homepage and lower-level pages formatted in a word processor represented the redesigned site. Both pages were used with a paper Web browser that provided standard functions, such as "Back," to be used by participants.

The second phase of the study consisted of three controlled field tests in which participants performed the same tasks as those performed with the paper prototypes, but on the current live site. Each participant chose the location for the field test, typically a student computer lab or faculty office.

\section{Methodology}

\section{Participants}

Eleven individuals participated in the study: five graduate students, five undergraduate students, and one faculty member. Student participants were recruited through departmental e-mail lists in the English and History departments. I personally recruited the faculty participant. Six of the study participants had conducted research of some kind in an archives or special collections library (one undergraduate, four graduates, one faculty). Four (one undergraduate, two graduates, one faculty) had previous experience using the Lilly Library Web site, principally for checking the Library's hours or the dates of an exhibition.

\section{Procedures}

Four participants used a paper version of the current Lilly Library Web site (Site A) and four used a paper prototype of a redesigned site (Site B). The groups were evenly divided between undergraduate and graduate students. The remaining three participants, including the lone faculty member, took part in field tests in which they used computers and browsers of their own choosing.

The testing activities for each participant began with reading and signing the consent form. Then the participants completed a questionnaire that asked for information about their experience in using computers, with special collections libraries in general, and with the Lilly Library Web site.

The facilitator, using a script to guard against influencing the participants unduly, conducted the testing, and, as schedules allowed, was assisted by a note-taker. Notes were recorded on a standard form to indicate which pages and links were selected by each participant, using numbers assigned to each paper prototype page. Note-taking forms also provided space for recording participant comments and the 
note-taker's observations. In addition, with the exception of the field tests, each testing session was audiorecorded.

Participants were asked to complete a series of five tasks, which were presented in a random order that was unique for each participant. In brief, the tasks were to:

- find a book

- find photographs in a manuscript collection

- find sheet music

- find fellowship and travel information

- find exhibition information

Each participant was presented with a card bearing a task question and asked to read and restate the task in his or her own words. They were also instructed to "think aloud" as much as possible to allow the facilitators to better understand their actions. There was no time limit attached, and participants were told they could quit the task at any point if they felt that is what they would do in a real-life situation. Once one task was completed, participants could move on to the next task. To mitigate the effects of knowledge gained during one task influencing the next task, cards were randomly presented, one at a time, for each participant.

In a paper prototype test, facilitators may have more interaction with participants than in a test of an electronic interface since, at the very least, the facilitator has to produce the resulting page each time the participant clicks on a link. In some cases, because the paper prototype of a Web site is limited to what has been created ahead of time, it becomes necessary for the facilitator to improvise, as in the case of a participant who conducts a search for a book within a manuscript database. In such a situation, the facilitator might report that the result yielded no useful records and ask the participant what he or she would like to do next.

After a participant finished all the tasks, the facilitator conducted a post-test interview with four follow-up questions. Facilitators shared with participants the version of the homepage that was not used during their particular test, inviting them to compare it to the one they had seen previously and to note their likes and dislikes.

\section{Results}

\section{Task 1: Finding a book}

"Recently, you were watching a television program on collecting mystery novels. It reported that a first edition of The Maltese Falcon by Dashiell Hammett (published in 1930) could sell for as much as $\$ 65,000$. You wonder what 
a $\$ 65,000$ book looks like. How would you find out if the Lilly Library has a first edition of this book? What information would you need to request the book at the Library?"

Successful completion of the task involved finding the link to the library catalog (IUCAT), identifying IUCAT as a useful resource, conducting a search, and distinguishing between different records to find a first edition with a known date.

Nine of the eleven participants were able to successfully complete this task, and a tenth found the correct record but failed to identify the call number. Nine of eleven participants indicated the appropriate top-level menu item that leads to the library catalog as his or her first step in completing the task: "Collections" in Site A and field test, and "Find a book or manuscript" in Site B.

Four participants (two undergraduate, two graduate) verbally expressed doubts about using the library catalog for this task. Of these, two stated they did not believe that Lilly Library materials were listed in the IUCAT at all. Another two specifically cited text on the page below the link to IUCAT, which warned users: "Approximately $45 \%$ of Lilly Library books are currently in the online catalog." This text prompted them to doubt the utility of searching the catalog. Of the two citing the $45 \%$ figure, the undergraduate participant continued to use the catalog anyway and completed the task, but the graduate participant decided not to use IUCAT at all and gave up on the task.

\section{Task 2: Finding photographs in a manuscript collection}

"You are researching the film Citizen Kane written and directed by Orson Welles. Your professor told you that the Lilly Library has some of Welles's personal papers, including photographs related to his various film projects. Where would you look to find out if the Lilly Library has photographs relating to Citizen Kane?"

Successful completion of this task involved finding some record of the Welles manuscript collection that includes photographs. Possible places to find this information included: the collection description, the guide to the collection, and the record for the collection in the library catalog.

Eight of eleven users were able to complete this task. Of those who were unable to do so, all were graduate students. Ten users began the task with appropriate top-level menu choices: those using Site A (including participants in the field test) selected "Collections" to begin. The results for Site B users were more varied: two began by clicking on "Find a book or manuscript" and one began with a site search. 
The researcher expected that participants would search the database of manuscript collection descriptions to complete this task, but they all chose other routes. Three (all using Site A) searched IUCAT. Three (all using Site B) conducted site searches. Four found the direct link to the guide, and one did some desultory clicking around the site before saying that, realistically, she would "just call the library." It should be noted that two of the three users who did not complete the task successfully found a record of the Welles manuscript collection but did not recognize that photographs were included in the collection.

Designing this task to test the usability of manuscript information on the Web site may have been unduly complicated by asking participants to find photographs. One graduate student who did not complete the task noted during her examination of the guide to the Welles papers that she "did not think of photographs as papers." Both Site B users who clicked first on "Find a book or manuscript" commented that they were not sure if photographs were included under this heading. One participant who used IUCAT said that she did not know how photographs are cataloged. Another participant who did complete the question said she did not understand the meaning of the number in parentheses following the title, Citizen Kane, in the collection guide. The number indicates how many photographs in the collection relate to the particular film title, although this is not explained in the guide itself.

\section{Task 3: Finding sheet music}

"You are looking for a copy of the sheet music for the song "Home on the Range." Where would you look to find out if the Library has a copy of this music? What information would you need to request this music at the Library?"

Successful completion of this task involved finding a call number for the sheet music of the song "Home on the Range." Nine of the eleven participants completed the task. One graduate student working on the field test almost completed the task by locating records for several items of sheet music for the song. In the end, she decided to e-mail the results to herself and so did not identify a call number. Another undergraduate student (Site A) did not complete the task. Overall, participants had more trouble completing this task than any of the others.

Eight of the eleven participants clicked on appropriate top-level links to begin the task. Two of the four Site A users, and all of the field test participants, clicked first on "Collections." Three of the four Site B users initially clicked on "Find a book or manuscript." Six of the participants whose first choice of a link was appropriate went on to select "Sheet Music" next. However, on the "Sheet Music" page, 
several users experienced confusion over identifying links ("Is this clickable?") and interpreting headings ("Is Sam DeVincent the composer?"). Though data were not collected on the time participants spent completing each task, completion of this particular task did take subjects longer, when measured in number of clicks. Some subjects found the database in as few as four or five clicks, but four participants required many more: specifically, 11, 12, 15, and 19. Even those who completed the task using relatively few clicks often scrolled up and down the text-heavy "Sheet Music" page to find the appropriate link to the database.

\section{Task 4: Finding fellowship and travel information}

"You are a researcher planning a visit to the Lilly Library. Does the Library offer any advice on traveling to Bloomington? Does the Library offer any monetary awards to help finance travel expenses?"

Successful completion of this task involved finding information about both research fellowships and travel on the Web site. In both Sites A and B, travel information is part of a larger page entitled "General information." Fellowship information has its own page, accessible via a direct link contained in a small secondary menu on the homepage of Site A. In Site B, it is reached via the "Programs and Services" page.

Nine of the eleven participants were able to locate both pages of information. Of the remaining two users, one found fellowship information only (using Site A); the other found travel information only (using Site B), although she did reach the "Programs and Services" page with the link to "Fellowships."

All four participants using Site B selected appropriate top-level links to begin, as did two of the four Site A users and two field test participants. A third Site A user began with a site search. Only one participant recognized and clicked on the direct link to "Fellowships," present on the Site A and field test homepages.

Connections between travel and fellowship information on the Web site were not obvious to participants. Two identified a link to travel information on the fellowships page only after much scanning. Three participants who completed the task expressed a lack of confidence about finding at least one piece of the information. An undergraduate student (during a field test) found travel information easily, but she said she probably would have given up on finding fellowship information in a real-life situation (although in the testing situation she performed several site searches and eventually found the fellowship information). One graduate student (Site A) adopted a scattershot approach, using nine clicks to complete the task. Another graduate student who used a site search to complete the task (Site A) com- 
mented, "I search when I don't see anything obvious to click on." Two undergraduates displayed a lack of understanding of the term "fellowships." One graduate student commented that "travel grants" would be a better term.

\section{Task 5: Finding exhibition information}

"You are thinking about taking some family members from out of town to visit the Lilly Library, but you aren't sure what is on exhibition. Find the title of the exhibition currently on display in the Library's Main Gallery."

Successful completion of this task involved finding the title of the exhibition currently on display at the Lilly Library. All sites tested had exhibition titles and dates listed in a sidebar on the homepage. Site A and field test also had top-level menu items entitled "Exhibitions and Events." Exhibition information on Site B was found via the "Programs and Services" link.

All participants completed this task. Site A and field test participants clicked on "Exhibitions and Events." Two commented that, while they saw the side bar on the homepage, they were not sure what that listed, so they clicked on "Exhibitions." Of Site B users, one clicked directly on the side bar that links to the full calendar; the others clicked first on "Programs and Services," and then on "Exhibitions," which links to the full exhibition calendar. Results for Site A and field test were possibly skewed in this task by the use of leading vocabulary: the word "exhibitions" made it easier for subjects to find the appropriate link.

\section{Analysis}

By its nature, the results of any kind of Web site usability testing are specific to the individual Web site being examined. In this analysis, qualitative results relating to the Lilly Library site will be extrapolated to identify usability issues relevant to other special collections library Web sites.

The results of almost every task raised questions about the vocabulary selected for headings and menus. In designing the tasks, I was primarily interested in how meaningful the term "collections" is to users. In Site B, the link text "Find a book or manuscript" replaced "collections" to give users a more concrete idea of what function is found behind the link. Study results revealed that participants displayed little hesitancy when selecting the link "Collections" in Site A, whether because of its inherent meaning or because of the lack of compelling alternatives. The text link "Find a book or manuscript," however, did provoke confusion in some Site B participants who doubted that information about photographs and sheet music might be accessed there, too. The more "function-oriented link" (as phrased) was 
interpreted in an exclusionary way. Unless the "Find a book or manuscript" link can be made more inclusive of other formats (changed perhaps to "Find library materials"), the "Collections" heading may be preferable.

Other terminology problems involved language specific to libraries and research. The question of what types of materials are included in the categories "manuscripts" or "papers" puzzled both undergraduate and graduate participants. The term "fellowship" was poorly understood, particularly by undergraduates. Given that undergraduates are not a primary audience for fellowships, this terminology problem is less critical for the success of the site.

Results relating to language that is difficult to understand and menu items that are troublesome to choose among are common in library usability studies. ${ }^{12}$ This study shows that reasonably specific library terms can be successfully used as links, as in the case of "collections," but that success depends on the context of the link. A small number of links with distinct meanings is necessary. Care should be exercised in using specific language, as indicated by those study participants who wondered if sheet music could be found under "Find a book or manuscript." McMullen cites a similar result in which subjects were unable to determine where to search for journal holdings when the homepage link to the online catalog was labeled "Books."13

Special collections libraries must be conscious about the use of specialized vocabulary. In this study, even a graduate student with some experience working in special collections libraries expressed some doubt about whether photographs might be found in a collection of "papers." Annotations for links, library FAQs, and guides to research in special collections can all contribute to helping users understand the myriad materials that may be found in a special collections library.

The placement of a link and the text surrounding it comprise the link context, which caused problems in two different tasks, in two different ways. Several users in Task 1 expressed doubts about the utility of the online catalog after reading the text accompanying the link to the catalog, which cautioned "only $45 \%$ of Lilly Library holdings" were included in the catalog currently. While this is clearly important information to a comprehensive search, usability test results indicate it may be desirable to separate it somehow from the link to the catalog, lest users be discouraged from using the catalog at all. However, it is possible that this problem may not be so prevalent in users outside the testing environment. Any testing environment, especially those using a "think-aloud" protocol, can cause participants to

12. See Battleson et al.; Benjes; and Dickstein, for example.

13. McMullen, "Usability Testing," 20, n4. 
read Web pages more thoroughly than they might do when using Web sites in their daily activities. ${ }^{14}$ In other words, test participants may be paying more attention to this information than would typical users.

The other link context issue involved a lack of context rather than too much context. In Task 5, several users noticed the exhibition and event sidebar on the homepage but were unsure of what exactly was listed there. The addition of a list label would improve this already efficient element of the site.

Careful attention to link context will improve the design of special collections library Web sites. It is easy to overwhelm the user, particularly when explaining the often complex variety of catalogs, finding aids, lists, and databases. Providing clear routes to common paths of resource discovery, such as the online catalog, must be balanced against providing the very specific information needed by expert users and library staff.

Kupersmith lists some "best practices" on the Web site "Library terms that users understand." ${ }^{15} \mathrm{He}$ advocates usability testing and avoiding problematic terms. But when specialized terms must be used, he lists ways to give context to menu choices and to expand on ambiguous terms in intermediate pages.

An effective search is another strategy for mitigating problems with terminology and menu choices, as well as avoiding text-heavy context for links. If users can search for information about a library's collection independent of format, then they can avoid what may be difficult menu choices. Providing access to all collections information in the online catalog is one way to accomplish this. A well-crafted site search that includes results from manuscript finding aids as well as other resources is another possible solution. Some users will likely still need help understanding the results, either through online FAQs, contextual hints, or easy access to online reference assistance.

Though participants in this study did not show a distinct preference for searching over menu navigation, participants using Site B (with its more prominent search box) did use a site search more often to complete tasks. This was particularly true for Task 2, the activity in which participants were asked to find information about photographs in a manuscript collection, where searching was a popular strategy when the subject was unsure what to choose in the main menu.

14. Snyder, Paper Prototyping, 303.

15. John Kupersmith, "Library Terms That Users Understand," available online at www.jkup.net/ terms.html (accessed Sept. 5, 2008). 
The results relating to terminology and link context provide the basis for some specific questions for those designing special collections Web sites. Other outcomes from this study offer more generic insight into Web design standards and guidelines. Task 3, the sheet music activity, included several participants who could not find links or could not decide if text was clickable. These problems can be addressed by adhering to usability guidelines that suggest all links should be underlined and be presented in a different color than surrounding text. ${ }^{16}$

The structure of the Web site can also be improved, as demonstrated in the results of Task 4. In this case, it will be necessary to create more explicit and findable links between related entities, such as research fellowship information and the travel information that applicants may need to plan a research trip. This type of information is important for many special collections libraries, and careful attention to its clear organization is warranted.

\section{Conclusion}

Though modest in scope, this study does provide some useful perspective on the organization of special collections library Web sites. In summary, it is necessary to find a balance between the specialness of our materials, and the words we use to describe them, and common Web standards that should be employed to create Web sites useful to all our patrons. Most users are able to navigate special collections Web sites, whether or not they have experience working with special collections. Problems tend to center on lack of context for the information online or general Web design problems. Special collections librarians do not have to avoid using all specialized terminology on their Web sites, if they use the terms in unambiguous ways and support understanding through unobtrusive contextual clues.

Following Web usability design guidelines regarding such seemingly mundane matters as the appearance of links is essential to providing an efficient experience for users. All users are capable of navigating a special collections Web site, but they may have questions about what they find there and how to access it. Convenient links to e-mail or instant messaging reference help are the obvious way to bridge that gap, but conforming to standards of Web design will also help to minimize the gap. Usability testing allows one to see a Web site through a user's eyes. The results are likely to point out new problems, confirm known problems, and, if you are lucky, illuminate things that the site is doing right. Usability testing, however informal, should have a place in the organization and design of any library Web site.

16. Jakob Nielsen, "Guidelines for Visualizing Links," Jakob Nielsen’s Alertbox (May 10, 2004), available online at www.useit.com/alertbox/20040510.html (accessed Sept. 5, 2008). 
The $42^{\text {nd }}$ California International Antiquarian Book Fair

San Francisco, CA | February 2009

Friday 13 th - Saturday 14 th $\bullet$ Sunday 15 th

Concourse Exhibition Center

635 Eighth Street | San Francisco, CA | USA

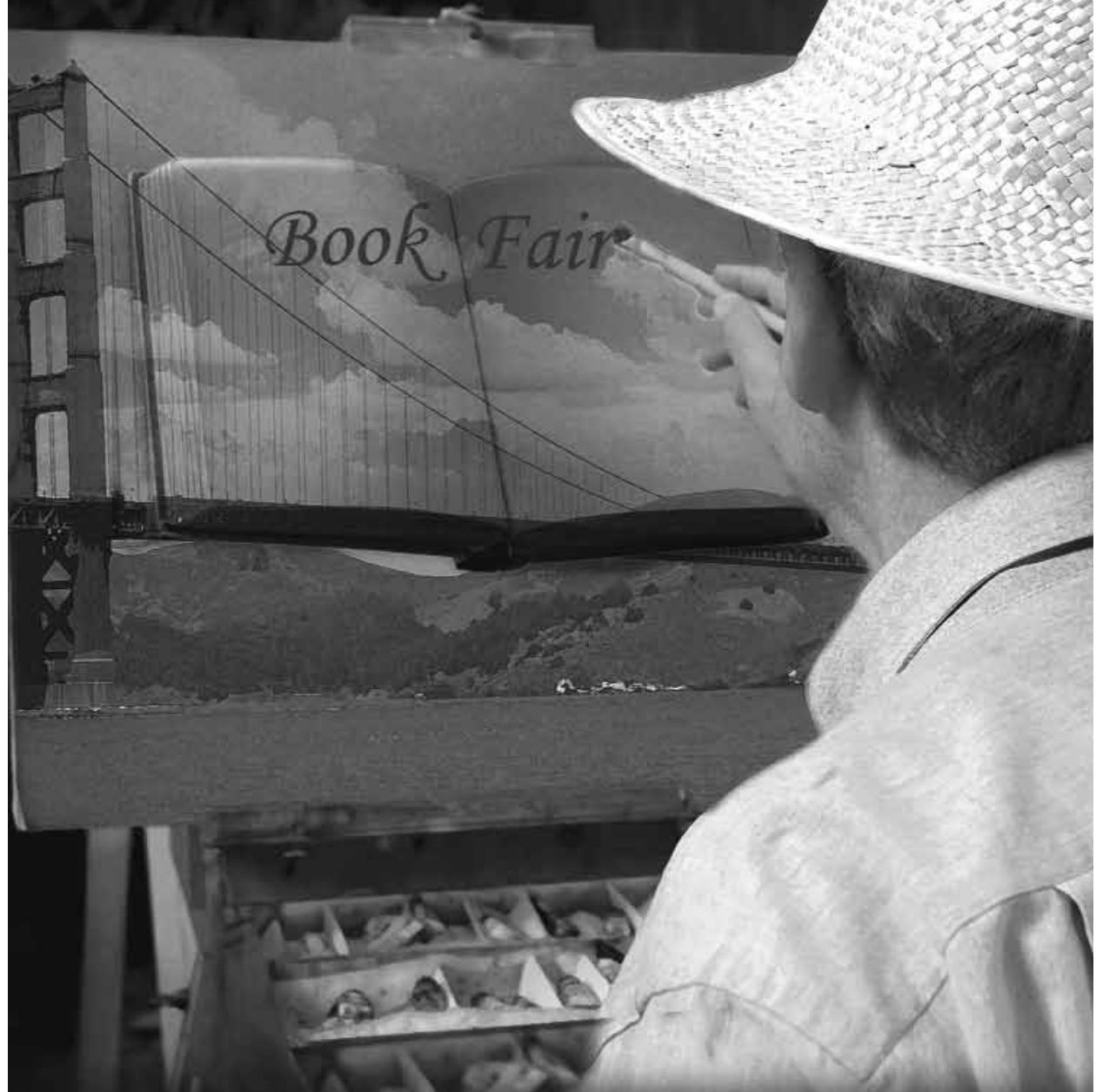

Featuring over 200 Booksellers from around the world $\$ 15$ Opening Admission | Friday

$\$ 10$ Regular Admission | Saturday • Sunday

For more information visit www.sfbookfair.com or call Winslow \& Associates at 800.454.6401

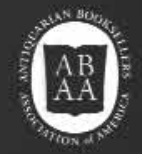

www.abaa.org

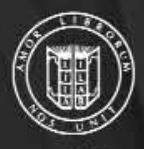

wwwilab.org 